\title{
Blending behavior of ethanol with PRF 84 and FACE A gasoline in HCCI combustion Mmode
}

\author{
Author, co-author (Do NOT enter this information. It will be pulled from participant tab in MyTechZone) \\ Affiliation (Do NOT enter this information. It will be pulled from participant tab in MyTechZone)
}

\begin{abstract}
The blending of ethanol with PRF (Primary reference fuel) 84 was investigated and compared with FACE (Fuels for Advanced Combustion Engines) A gasoline surrogate which has a RON of 83.9. Previously, experiments were performed at four HCCI conditions but the chemical effect responsible for the non-linear blending behavior of ethanol with PRF 84 and FACE A was not understood. Hence, in this study the experimental measurements were simulated using zerodimensional HCCI engine model with detailed chemistry in CHEMKIN PRO. Ethanol was used as an octane booster for the above two base fuels in volume concentration of $0 \%, 2 \%, 5 \%$ and $10 \%$.

The geometrical data and the intake valve closure conditions were used to match the simulated combustion phasing with the experiments. Low temperature heat release (LTHR) was detected by performing heat release analysis. LTHR formation depended on the base fuel type and the engine operating conditions suggesting that the base fuel composition has an important role in the formation of LTHR. The effect of ethanol on LTHR was explained by low temperature chemistry reactions and $\mathrm{OH} / \mathrm{HO}_{2}$ evolution. A strong correlation of low temperature oxidation reactions of base fuels with ethanol was found to be responsible for the observed blending effects.
\end{abstract}

\section{Introduction}

Blending of ethanol with gasoline is widely used in the transport sector. E22 or E25 ethanol-gasoline blends are utilized in Brazil [1]. In Australia, E10 and in Sweden E5 is being used by the transport vehicles [2]. This is mainly due to the ethanol's higher research octane number (RON) 108 [3], leading to a better anti-knock characteristics than commercial gasoline. Due to depletion of fossil fuel resources and the need for a clean and sustainable environment, efforts are under progress to find alternative fuels such as alcohols [4]. Alcohols due to their latent heat of vaporization which is 3-5 times greater than gasoline makes them a suitable fuel for the spark ignition engines [4]. The cooling effect caused by the high latent of vaporization helps to lower the intake manifold temperature and this leads to higher volumetric efficiency [4]].

It has been well established in the literature that the blending of ethanol with gasoline results in a non-linear behavior of RON [3, 5-8]. It has been reported that $10 \%$ of ethanol addition will cause a significant increase of RON [8]. The composition of the base fuel plays an important role in the non-linear RON response [으, 7]. Ethanol blending with PRF 91 and RON 91 gasoline was investigated and it was found that PRF 91 resulted in more non-linear behavior as compared to gasoline with RON 91 [3]. In addition to ethanol, the aromatic contents also affects the non-linearity and a decreasing trend for RON is observed for the base fuels with the greatest aromatic contents [7]. The base fuel octane number also plays an important role in the RON

Page 1 of 16 evolution and it has been found that the greatest increase in the RON was observed with base fuel having low RON [] ] The non-linearity with ethanol blending is explained using the blending octane number []․

In spark ignition engines, RON evolution is used to understand the non-linear blending behavior. This is mainly because the auto-ignition characteristic of the fuels for spark ignition engines is described with RON and MON [9]. It has been reported that RON and MON are not the ideal parameters to describe the auto ignition properties in HCCI combustion mode [10]. Recent work shows that Lund-Chevron HCCI fuel number is a better parameter to describe the auto-ignition quality for HCCI combustion mode [10]. In HCCI mode, Lund-Chevron HCCI fuel number will be used to understand the blending behavior of ethanol with gasoline.

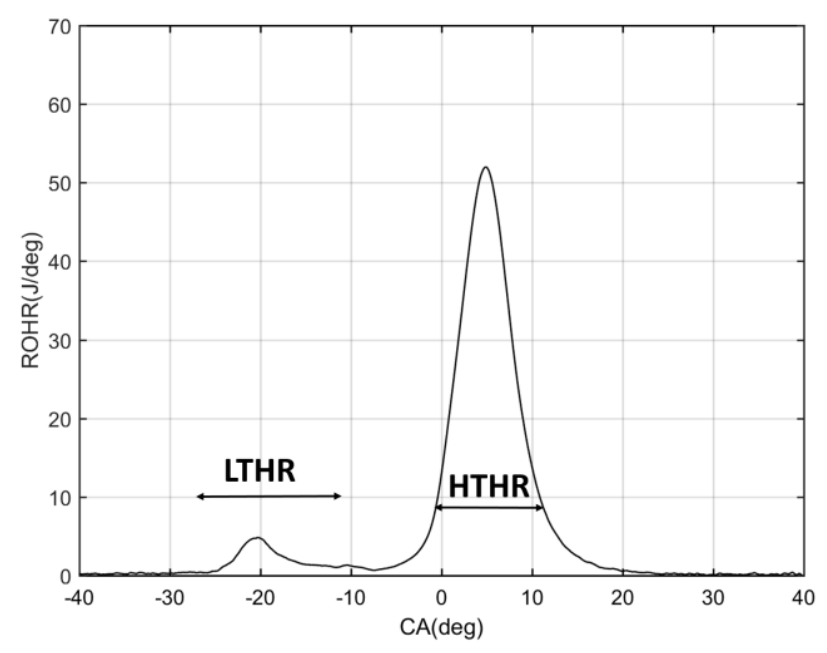

Figure 1 : Heat release rate

Figure 1 demonstrates the rate of heat release for one of the fuel blends: PRF 84 with zero percent ethanol, tested for this study. The fuel was tested in HCCI combustion mode. The figure shows two stages of heat release; a low temperature heat release (LTHR) and a high temperature heat release (HTHR). The LTHR is mainly due the peroxy $\left(\mathrm{RO}_{2}\right)$ and hydroperoxy $(\mathrm{QOOH})$ alky radicals chemistry. The low temperature chemistry starts by formation of alkyl radicals from fuel molecule through hydrogen abstraction by different radicals present in the system (e.g. $\mathrm{OH}, \mathrm{O}, \mathrm{HO}_{2}$ ) [11-13]. Once the alkyl radical is formed, it undergoes addition to molecular oxygen and forms peroxy radical $\left(\mathrm{RO}_{2}\right)$, which isomerizes to hydroperoxy alkyl radical (QOOH). Isomerization takes place through intramolecular hydrogen migration via a transition state ring[12,13]. Accordingly, the more sites available for hydrogen abstraction in the fuel molecule, higher the LTHR is. This 
explains why normal alkanes such as n-heptane exhibit higher LTHR compared to branched alkanes like iso-octane [14].

The region between LTHR and HTHR, where a reduction in reactivity is observed with increasing temperature, is called negative temperature coefficient (NTC) region [15]. n-Heptane exhibit significant LTHR and has NTC behavior [16]. The addition of ethanol acts as a radical scavenger; where it consumes the active radicals and mitigates the hydrogen abstraction from other fuel molecule such as n-heptane, which leads to a reduction of LTHR [16-18]. For low inlet air temperatures, the LTHR region is significant for the PRF mixtures [15]. When LTHR is present, the auto-ignition temperature is lower [15]. Another study was conducted to investigate the amount of LTHR by using oxygenated reference fuels in HCCI combustion [19]. Blends of n-heptane, iso-octane and ethanol were tested and it was found that ethanol has a quenching effect and helps to reduce LTHR [19].

The chemical reactions responsible for the two-stage ignition are explained using chemical kinetic modeling which is a useful tool to understand the behavior of engine experiments. Detailed kinetic models have been developed for this purpose [18, 20-23] and tested under engine related conditions. In addition, the chemical kinetic mechanism for ethanol was validated against experimental data from flow reactor, jet stirred reactor and ignition delay data [24].

Previous experiments were performed in SI, HCCI and CI combustion modes to understand the non-linear behavior caused by the addition of ethanol [25]. The experiments in HCCI conditions were performed at four different conditions: two corresponding to RON and MON and the other two in which the engine speed and inlet air temperature were varied independently. The non-linearity caused by the ethanol addition was observed in all four HCCI modes but the chemical effects responsible for the non-linear behavior were not addressed [25]. Previously ethanol blending with PRF 70 was explained using the

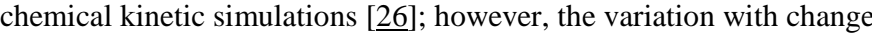
of base fuel composition was not addressed.

This study addresses the effect of ethanol blending with PRF 84 and FACE A (Fuels for Advanced Combustion Engines) gasoline which has a RON of 83.9 and MON of 83.5. Previously, the experimental investigation highlighted that the composition plays an important role in the non-linear blending behavior of ethanol with these two base fuels [25]. The combustion characteristics of FACE A and PRF 84 have previously been studied in shock tubes and rapid compressions machines[27, 28], jet stirred reactors [29], premixed flames[ $\underline{30}, \underline{31}]$, and HCCI engines [32].The chemical effect of ethanol blend is the focus of this work. It is difficult and unrealistic to model the real gasoline for chemical kinetics since it has many components. For this purpose, surrogates are developed that could help to closely replicate the chemical kinetics for real fuel. In order to understand the chemical effects for FACE A, a multicomponent surrogate for FACE A was used in the chemical kinetic simulations. Detailed heat release analysis and zero-dimensional simulation using HCCI model is used to explain these chemistry effects.

\section{Fuels}

Two fuels PRF 84 and FACE (Fuel for advanced combustion engines) A gasoline were used for this study. It is difficult to model real FACE A gasoline as it consists of hundreds of components. A surrogate for FACE A was instead used for the simulations. More details about the surrogate formulation is given by Ahmed et al. in [27, 33]. The composition of the FACE A surrogate are given in Table 1. The other properties of FACE A are given in the Appendix D. Previous studies have shown that multicomponent surrogates can better capture the low temperature and high pressure ignition characteristics of FACE A when compared to PRF 84 [27].

Table 1: FACE A surrogate composition by Ahmed et al. [27]

\begin{tabular}{|l|c|}
\hline FACE A & Composition percentage (\%) \\
\hline n-Butane & 7.7 \\
\hline iso-Pentane & 12 \\
\hline 2-Methylhexane & 10.3 \\
\hline n-Heptane & 10 \\
\hline iso-Octane & 60 \\
\hline
\end{tabular}

\section{Methodology}

\section{Experimental heat release analysis}

A Cooperative Fuel Research engine (CFR) was used to perform HCCI experiments with PRF 84 and FACE A. Details about the experiments and the procedures followed to obtain the results can be found in the previous publication of the author [25]. The HCCI experiments were performed at four different engine conditions and are described in the Table 2. The valve timing of the CFR engine is also shown in Figure $\underline{2}$.

Table 2: Four HCCI fuel numbers

\begin{tabular}{|l|l|l|}
\hline HCCI fuel numbers & Engine speed (rpm) & $\begin{array}{l}\text { Intake air Temperature }\left(^{\circ}\right. \\
\text { C) }\end{array}$ \\
\hline HCCI-1 (RON) & 600 & 52 \\
\hline HCCI-2 & 600 & 149 \\
\hline HCCI-3 & 900 & 52 \\
\hline HCCI-4 (MON) & 900 & 149 \\
\hline
\end{tabular}

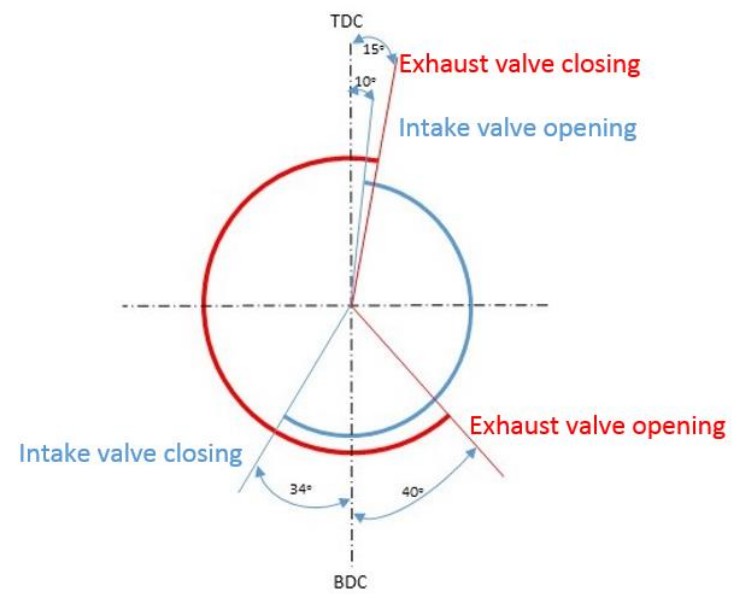

Figure 2 : Valve timing diagram for a CFR engine

Page 2 of 16 
The two HCCI conditions correspond to RON and MON conditions where as for the other two conditions, the speed and temperature were varied independently to investigate their effect. HCCI \# 4 was mentioned to be equivalent to the MON conditions in a sense that the speed $(900 \mathrm{rpm})$ and temperature of $149 \mathrm{C}$ is same. No experiment was performed with air/fuel mixture temperature. Similar to HCCI \# 1 and HCCI \# 3 experimental conditions, RON and MON prime have also been previously defined [34]. Ethanol was blended with PRF 84 and FACE A with percentages of $2 \%, 5 \%$ and $10 \%$. In-cylinder pressure was acquired for 188 cycles for each of the blends tested. In this study, the experimental pressure traces for four HCCI conditions and the geometrical engine data were used to perform heat release analysis. The heat release analysis was performed using first law analysis and the heat losses from the wall. The crevices and blow by losses were assumed to be negligible. More details on how the heat release analysis was performed can be found in Appendix A.

\section{Chemical Kinetic simulations}

CHEMKIN PRO (version.15142) was used to perform chemical kinetic simulations with 0 -D single zone engine solver [35]. The chemical kinetic mechanism for PRF 84 was adopted from Atef at al [11]. and validated against experiments from Alabbad et al [27]. For FACE A surrogate, the updated iso-pentane model by Bugler et al [36] and updated 2-methyl hexane model form Mohamed et al [37] were added to the model used for PRF 84 simulations and validated against ignition delay time data for FACE A from [27].

Initially, the motoring pressure trace was matched between the experiments and simulations. This provided an equivalent compression ratio to be used for the simulations. The chemistry was then turned on and the combustion phasing was matched. It was decided to take $10 \mathrm{~J} / \mathrm{CAD}$ as a criteria to match the combustion phasing. It was an arbitrary criteria but enough to get a good correlation between the experimental and the simulated heat release rate for comparison purposes. In order to match the combustion phasing, the intake temperature was varied until $10 \mathrm{~J} / \mathrm{CAD}$ was achieved. This was done for the case of zero ethanol concentration (PRF 84 and FACE A) with fixed (equivalent) compression ratio. Thereafter the temperature was kept constant and the compression ratio was varied with increasing ethanol concentration $(2 \%, 5 \%$ and $10 \%)$ to match the combustion phasing. The simulation approach is similar to that followed in experiments, wherein, the CR was increased to match the combustion phasing CA50 of 3 CAD (ATDC) when ethanol concentration is increased from 0 to $10 \%(\mathrm{v} / \mathrm{v})$. Appendix B shows the simulated and experimental compression ratios.

It was found that the compression ratios used for the simulations did not match with the experimental data. This could be due to the heat losses ignored in the simulations. It could also be attributed to the distortion of in-cylinder volume trace due to the mechanical deformation from the inertial, thermal and pressure forces [38]. It has been reported that the distortion of in-cylinder volume can cause error in the heat release analysis [ㅍ].

Table 3: Simulation baseline inputs.

\begin{tabular}{|l|l|}
\hline Experimental conditions & Simulated conditions \\
\hline $600 \mathrm{rpm} 52^{\circ} \mathrm{C}$ & $600 \mathrm{rpm} 92^{\circ} \mathrm{C}$ \\
$600 \mathrm{rpm} 149^{\circ} \mathrm{C}$ & $600 \mathrm{rpm} 149^{\circ} \mathrm{C}$ \\
$900 \mathrm{rpm} 52^{\circ} \mathrm{C}$ & $900 \mathrm{rpm} 90^{\circ} \mathrm{C}$ \\
$900 \mathrm{rpm} 149^{\circ} \mathrm{C}$ & $900 \mathrm{rpm} 145^{\circ} \mathrm{C}$ \\
\hline
\end{tabular}

Page 3 of 16
Table 3 shows the engine speed and intake temperature conditions used for the experiments and simulations. In order to match the combustion phasing for the experiments and simulation, the intake temperature for the simulations had to be increased. This could be due to number of reasons: 1) Lack of reactivity in the chemical kinetic model used for the simulations. Previously chemical kinetic models with reactivity problems have been reported under HCCI conditions [르, 39]. 2) The heat losses were ignored during the simulations. 3) In the simulations, the temperature is taken at intake valve closure where as for the experiments, intake air temperature was taken into account. 4) The simulations assume gas phase homogeneous assumption and do not take into account charge cooling effect, which could have been present in the experiments with ethanol addition. More details about the reasons for increasing the intake air temperature have been discussed in the previous publication on PRF70 by the authors [26].

Qualitatively, simulations provided good insights on the blending effect of ethanol on PRF84 and FACE A surrogate regardless of the increased intake air temperature.

\section{Results}

The symbols E0, E2, E5 and E10 corresponds to ethanol with percentages $0 \%, 2 \%, 5 \%$ and $10 \%$ respectively. The operating conditions for the experiments and the simulations are given in the captions.

\section{Experimental heat release}

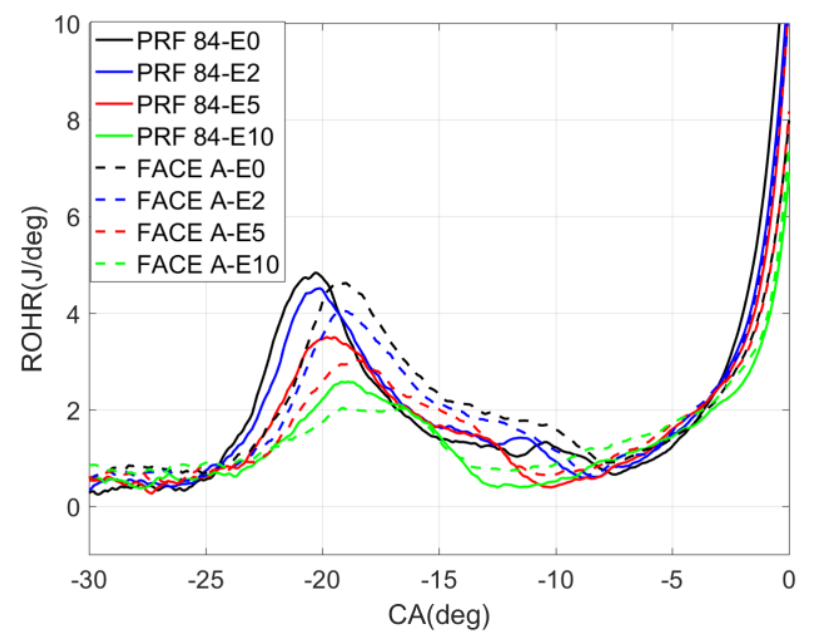

Figure 3: Experimental Low temperature heat release for PRF 84 and FACE A $, 600 \mathrm{rpm}, 52^{\circ} \mathrm{C}$

Figure 3 show the experimental heat release analysis for PRF 84 and FACE A with different ethanol percentages. FACE A and PRF 84 both had RON close to 84 but the composition is quite different. The low temperature heat release (LTHR) was found to be more pronounced for lower intake temperature of $52^{\circ} \mathrm{C}$. A maximum peak magnitude for LTHR was observed for the case of zero ethanol i.e. E0 for low intake air temperature. This was found to be true for both PRF 84 and FACE A. The peak magnitude of LTHR was found to be higher for PRF 84 as compared to FACE A with E0 taken as a datum point. These results are consistent with ignition delay measurements in rapid compression machines, which shows greater low temperature reactivity of PRF 84 compared to FACE A [27]. The greater reactivity is due to the 
presence of more n-heptane in PRF 84 which has an important role in the development of LTHR [15]. The presence of strong LTHR for both base fuels could be attributed to high compression ratios used at low inlet air temperatures to achieve constant CA50. The increased pressure due to high compression ratio tends to promote strong LTHR. With the addition of ethanol, the LTHR was suppressed for both PRF 84 and FACE A. This was also observed in another study where ethanol suppressed LTHR and the reactivity of the ethanol blends decreased with increasing ethanol content [40]. The addition of ethanol into heptane resulted in non-linear increase of octane number and it was found that the non-linear behavior could be due to the low temperature chemistry of n-heptane with ethanol [41]. Previous studies on ethanol blending with base fuels suggest a non-linear increase in the octane number $[\underline{3}, \underline{6}, \underline{8}, \underline{25}]$. This suggests that the ON non-linear behavior has a link with the suppression of LTHR region.

It has been previously found that a small addition of ethanol into base fuel can result in the significant increase of $\mathrm{ON}[\underline{3}, \underline{6}]$. Anderson et al highlighted that $10 \%$ of ethanol addition caused a significant increase in the RON of the blend [8]. Another study highlighted that with $30 \%$ ethanol addition by volume, the RON starts to converge to an octane number of neat ethanol highlighting that non-linear behavior does not exist after $30 \%$ addition [5]. Figure 3 clearly shows that with $10 \%$ ethanol addition, LTHR is reduced significantly. This again highlights that most likely the reduction of LTHR is linked to the non-linear blending behavior of ethanol. It was also observed that $2 \%$ ethanol addition (Figure 3 ) led to more reduction in the peak LTHR for FACE A than PRF 84, which highlights that ethanol addition was more effective for FACE A than PRF 84.

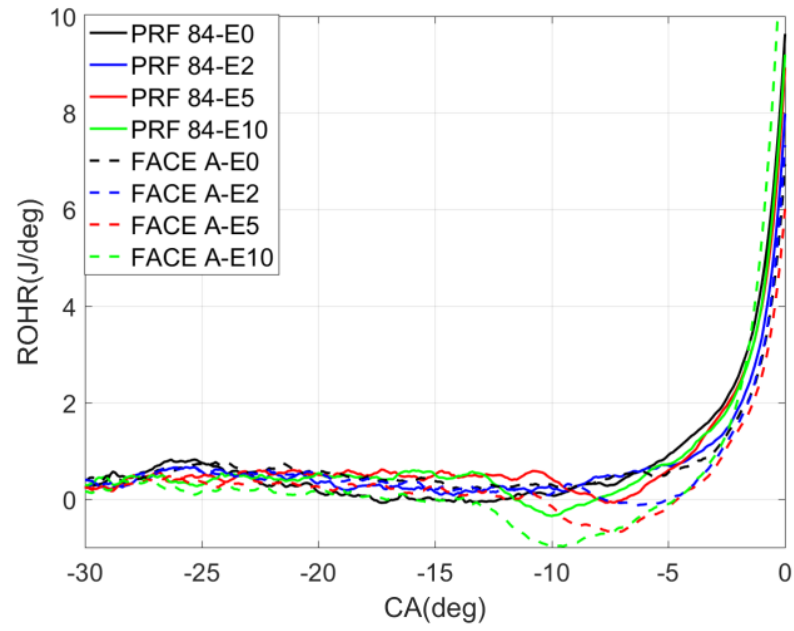

Figure 4 : Experimental Low temperature heat release for PRF 84 and FACE A , $600 \mathrm{rpm}, 149^{\circ} \mathrm{C}$

For higher inlet air temperature, the LTHR was either very small or negligible for the speed of $600 \mathrm{rpm}$ (Figure.4). This is consistent with another study on PRF 0-100 with increasing inlet air temperatures, wherein it was found that with inlet air temperature of $150^{\circ} \mathrm{C}$ and PRF 85-100, LTHR was suppressed [15]. Both PRF 84 and FACE A showed negligible LTHR at $600 \mathrm{rpm}$ and $149^{\circ} \mathrm{C}$ conditions. The addition of ethanol had somewhat same affect for both the base fuels.

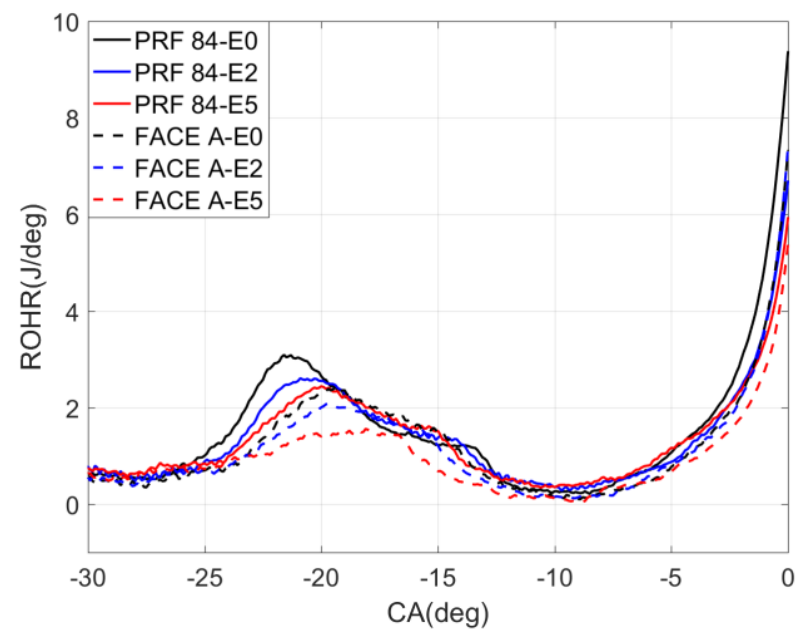

Figure 5 : Experimental Low temperature heat release for PRF 84 and FACE A , $900 \mathrm{rpm}, 52^{\circ} \mathrm{C}$

With the increase in the speed from $600 \mathrm{rpm}$ to $900 \mathrm{rpm}$ and constant inlet air temperature of $52^{\circ} \mathrm{C}$, it was observed that the peak LTHR reduced for all ethanol percentages (Figure 3 and Figure 5). This was true for both the base fuels. This is consistent with the finding of Ida et al [14] that LTHR is suppressed with the increasing speed. The peak magnitude of LTHR for E0 was higher for PRF 84 than FACE A. The reduction of LTHR followed a linear decrease with ethanol addition. This was found to be true for both FACE A and PRF 84.

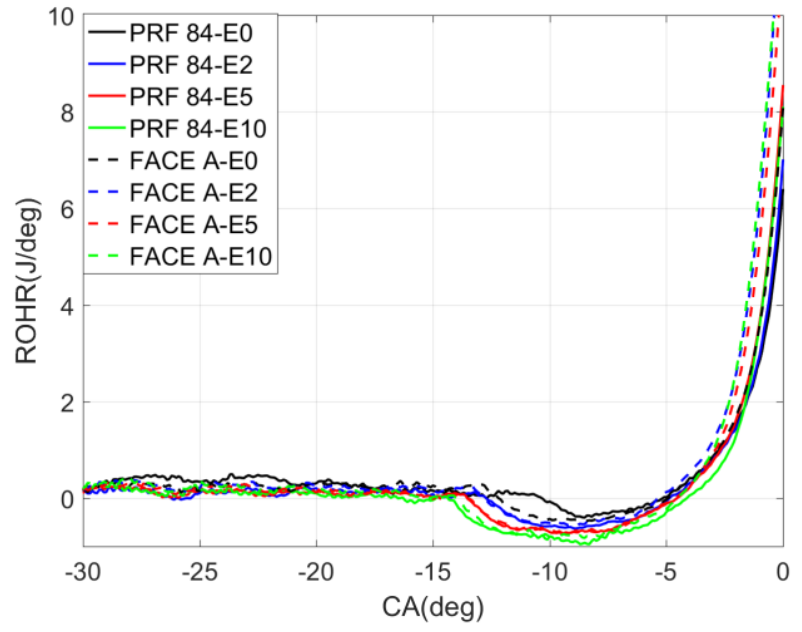

Figure 6: Experimental Low temperature heat release for PRF 84 and FACE A, $900 \mathrm{rpm}, 149^{\circ} \mathrm{C}$

With simultaneous increase in both speed and temperature, the effect of ethanol blending on LTHR is negligible or small (Figure 6). The combustion phasing for the high temperature heat release was found to be similar for both FACE A and PRF 84. 
Overall, it could be concluded that the low temperature reactions are quite dominant for lower intake air temperatures. The base fuel composition has an important role in the peak magnitude of LTHR. Previous experimental study by Waqas et al [25] has shown that ethanol blending behavior is different for FACE A and PRF 84. This was found to be true for all four HCCI conditions.

In order to explain some of the above observations from the kinetic point of view, simulations were performed. The procedure adopted to obtain the simulated results are explained earlier.

\section{Simulated Results}

Simulations were able to qualitatively replicate the experimental behavior and provided insightful understanding of the kinetics occurring in the cylinder. The reasons to increase the inlet air temperature for the simulations have been explained earlier. As discussed before, 10J/CAD was kept as a criteria to match the combustion phasing.

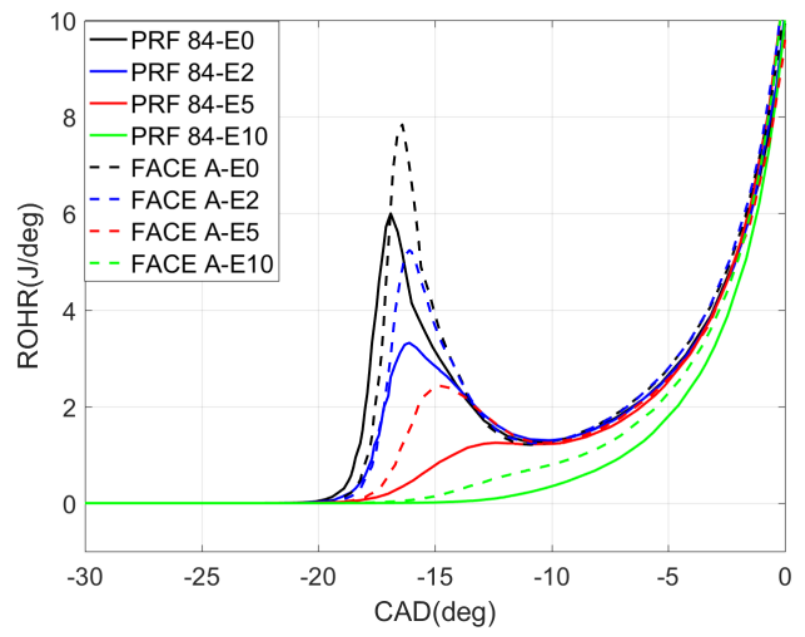

Figure 7: Simulated low temperature heat release for PRF 84 and FACE A, 600 rpm, $92^{\circ} \mathrm{C}$

Figure 7 shows the simulated LTHR regions at $600 \mathrm{rpm}$ and $92^{\circ} \mathrm{C}$ with different ethanol content for PRF 84 and FACE A respectively. With the addition of ethanol, LTHR region was suppressed for both PRF 84 and FACE A. For E2 (2\% ethanol), LTHR decreased significantly almost to half compared to E0. The suppression of LTHR in the presence of ethanol has also been previously reported and ethanol acts as a radical scavenger and reduces LTHR [15-17, 42, 43]. Ethanol reacts with the active radicals (i.e $\mathrm{HO}_{2}$ and $\mathrm{OH}$ ) through a chain termination pathway and hinders them from reacting with the fuel. When compared with PRF 84, the rate of LTHR reduction is quite different for FACE A. For E10, LTHR was completely suppressed for PRF 84 but for FACE A, a small LTHR is observed.

As discussed previously, abstraction of $\mathrm{H}$ atoms from fuel species by $\mathrm{OH}$ leading to a radical pool is the main trigger for the chemistry of low temperature auto-ignition [27]. The two most important radicals in the LTHR process are $\mathrm{OH}$ and $\mathrm{HO}_{2}[\underline{26}]$.

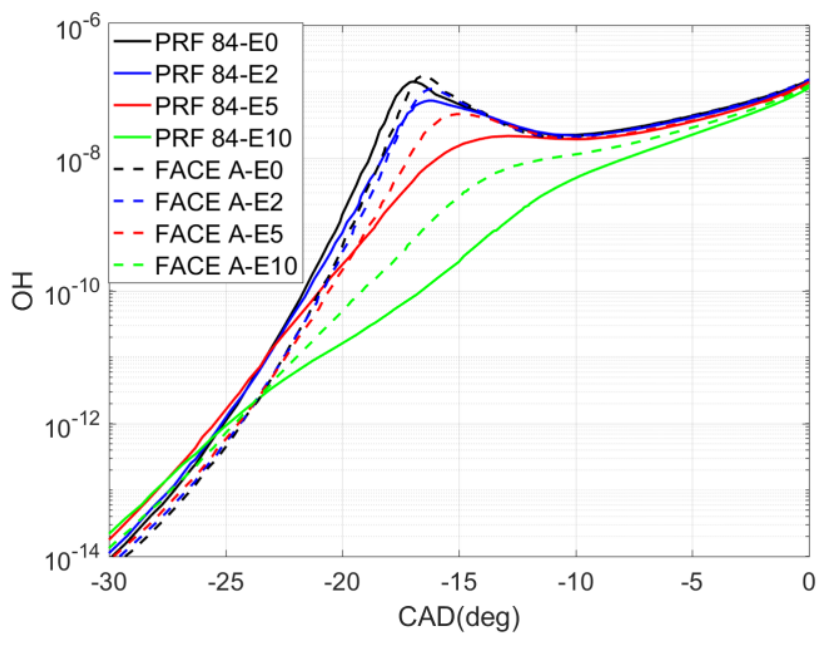

Figure 8: $\mathrm{OH}$ mole fraction for PRF 84 and FACE A, $600 \mathrm{rpm}, 92^{\circ} \mathrm{C}$

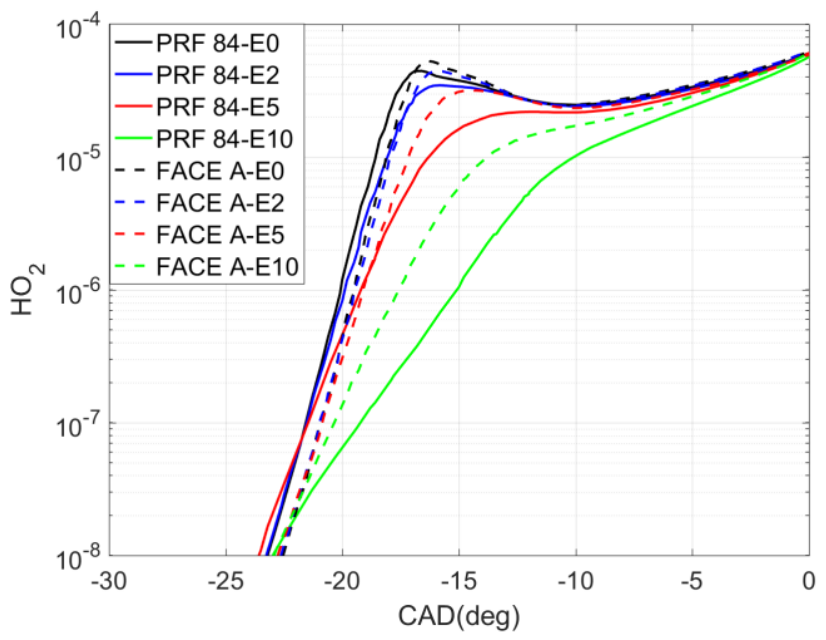

Figure $9: \mathrm{HO}_{2}$ mole fraction for PRF 84 and FACE A, $600 \mathrm{rpm}, 92^{\circ} \mathrm{C}$

Figures 8 and 9 describe the evolution of $\mathrm{OH}$ and $\mathrm{HO}_{2}$ produced from the simulated LTHR at $600 \mathrm{rpm}, 92^{\circ} \mathrm{C}$. The peak mole fractions lay in the same range of -20 to $-10 \mathrm{CAD}$, which is the region of LTHR. This explains that these two radicals have an important role in the development of LTHR region. The evolution of $\mathrm{OH}$ and $\mathrm{HO}_{2}$ in the region of LTHR can be explained by understanding the low temperature hydrocarbon oxidation and auto-ignition chemistry. The process starts with fuel radical reacting with oxygen molecule to form peroxy radical. The internal $\mathrm{H}$ migration (isomerization) and further addition of oxygen molecule leads to the formation of ketohydroperoxide, which eventually decomposes producing $\mathrm{OH}$ radicals. This leads to build a pool of $\mathrm{OH}$ radicals. At the same time, when the temperature is increasing during the LTHR event, competing reactions are also occurring and the peroxy radical can lead to the formation of alkene and $\mathrm{HO}_{2}$. This $\mathrm{HO}_{2}$ react with the fuel to form $\mathrm{H}_{2} \mathrm{O}_{2}$ which rises then followed by decay and an increase in the mole fraction of $\mathrm{OH}$ and $\mathrm{HO}_{2}$ can be interpreted from the chemical reactions explained above leading to the formation of $\mathrm{OH}$ and $\mathrm{HO}_{2}$. More details about the mechanism leading to the formation of $\mathrm{OH}$ and $\mathrm{HO}_{2}$ radicals can be found in $[12,13, \underline{27}, \underline{44]}$. The peak magnitude of $\mathrm{OH}$ in Figure $\underline{8}$ highlights the region of LTHR followed by decay in the intermediate temperature region known as negative temperature coefficient (NTC)

Page 5 of 16 
region. A further increase in $\mathrm{OH}$ leading to $\mathrm{HTHR}$ can be understood from the decomposition of $\mathrm{H}_{2} \mathrm{O}_{2}$ to $2 \mathrm{OH}$. The $\mathrm{HO}_{2}$ follows somewhat the same trend as $\mathrm{OH}$ but the relative magnitude of mole fraction for $\mathrm{HO}_{2}$ is less as expected. The above chemical explanations is true for both FACE A and PRF 84 at $600 \mathrm{rpm}$ and $92^{\circ} \mathrm{C}$. PRF 84 and FACE A shows different $\mathrm{OH} / \mathrm{HO}_{2}$ evolution showing that the chemical composition/chemistry of the base fuel has an important role in the blending of ethanol.

The decrease in the evolution of $\mathrm{OH}$ and $\mathrm{HO}_{2}$ with ethanol addition can be understood from the chemical reactions that occur when ethanol reacts with the base fuel. The $\mathrm{C}-\mathrm{H}$ bond close to hydroxyl group $\mathrm{OH}$ has weak bond energy and with the pool of $\mathrm{OH}$ radicals around is easily abstracted.

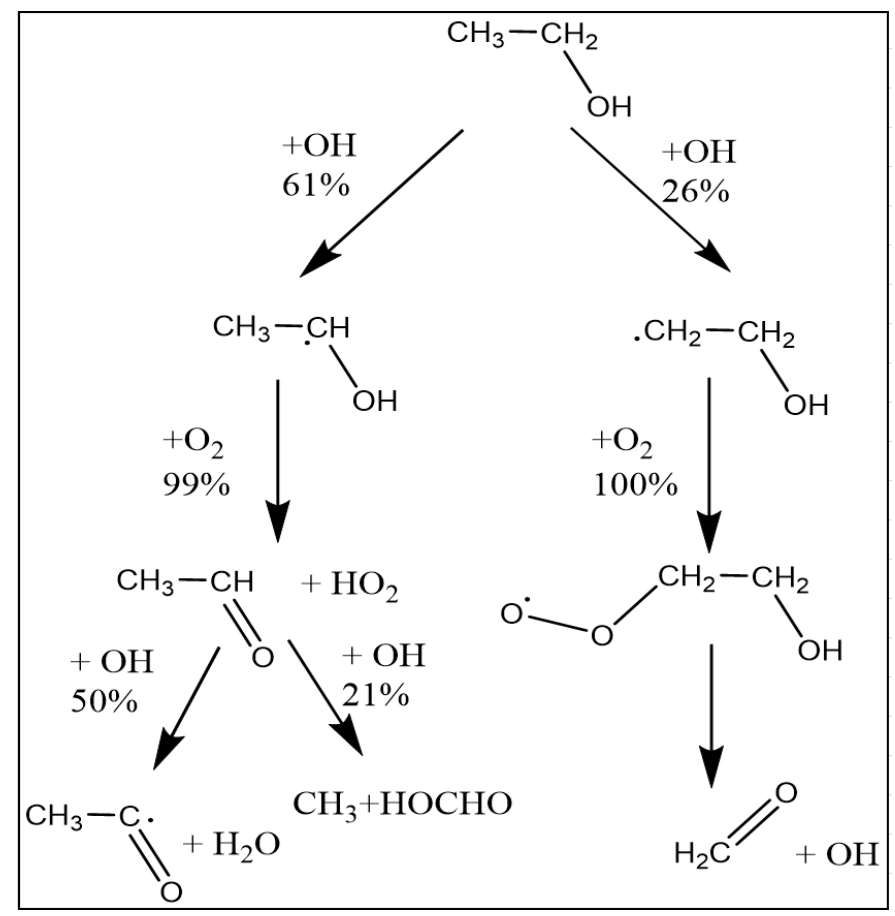

Figure 10: Flux analysis for ethanol in PRF 84/ethanol mixture at $600 \mathrm{rpm}, 92$ ${ }^{\circ} \mathrm{C}$

Figure 10 shows the flux analysis for ethanol at $10 \%$ ethanol consumption. $87 \%$ of ethanol reacts with $\mathrm{OH}$ producing primary $\left(\mathrm{CH}_{2} \mathrm{CH}_{2} \mathrm{OH}\right)$ and secondary $\left(\mathrm{CH}_{3} \mathrm{CHOH}\right)$ radicals. The major product is the secondary radical, which undergoes a chain termination pathway and considered as an ideal radical sink pathway. In this way, ethanol acts as a radical scavenger for $\mathrm{OH}$ radical leading to the reduction of LTHR region. This decreasing trend of $\mathrm{OH}$ mole fractions with ethanol addition (Figure 8) correlate well with the explained chemical reactions.

It is also observed that with the small addition of ethanol (E2), LTHR reduces significantly in Figure 7 . In the beginning, the $\mathrm{OH}$ radicals produced by different reaction pathways exhibited by the fuel radicals are larger in number and with the small addition of ethanol, it is most likely that ethanol will scavenge many $\mathrm{OH}$ radicals leading to a drastic decrease in LTHR. As the ethanol concentration is increased, the base fuel quantity is reduced which leads to less number of $\mathrm{OH}$ radicals for the ethanol to scavenge and therefore it is observed in Figure 7 that the rate of LTHR decreases with the ethanol addition.

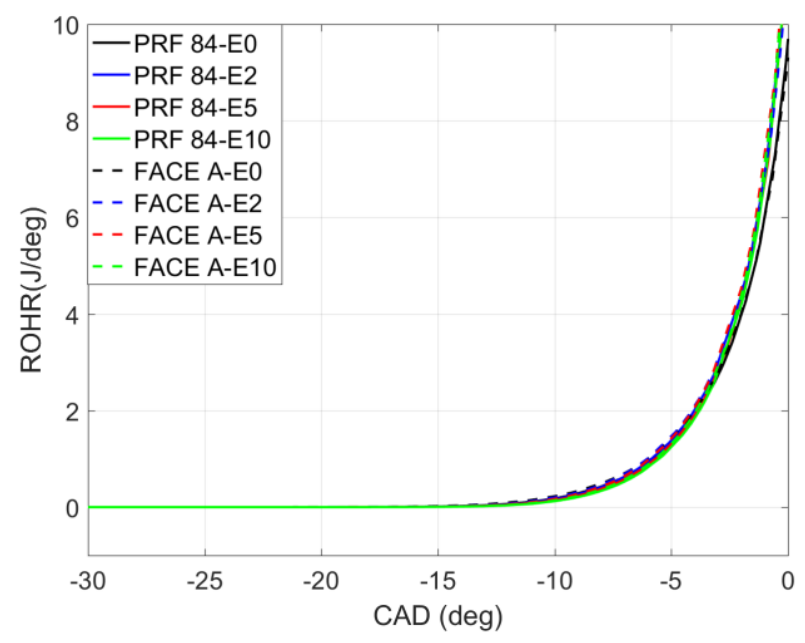

Figure 11: Simulated low temperature heat release for PRF 84 and FACE A, $900 \mathrm{rpm}, 145^{\circ} \mathrm{C}$

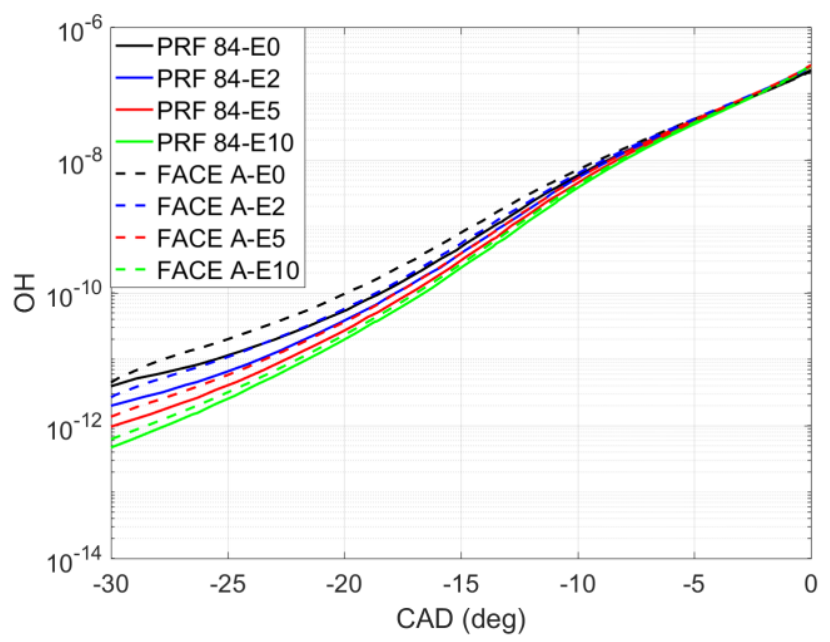

Figure 12: $\mathrm{OH}$ mole fraction for PRF 84 and FACE A, $900 \mathrm{rpm}, 145^{\circ} \mathrm{C}$

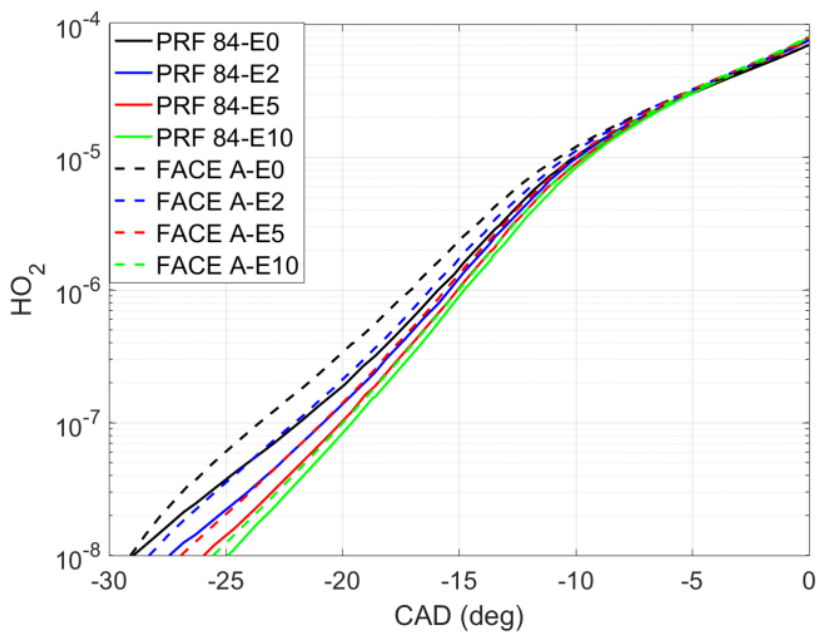

Figure 13: $\mathrm{HO}_{2}$ mole fraction for PRF 84 and FACE A, $900 \mathrm{rpm}, 145^{\circ} \mathrm{C}$

Page 6 of 16 
Figures 11-13 show the combined effect of speed and temperature on ethanol blends. It is obvious that no LTHR is observed for both FACE A and PRF 84, which is consistent with the experimental heat release analysis. The $\mathrm{OH} / \mathrm{HO}_{2}$ evolution also did not show any peak increase in radical mole fractions as observed for the low intake temperature condition (Figure 8 and Figure 9). This indicates the absence of LTHR with increasing inlet temperature. As previously mentioned, the low temperature chemistry requires the isomerization of the peroxy radical $\left(\mathrm{RO}_{2}\right)$ into hydroperoxy alkyl radical $(\mathrm{QOOH})$. However, at elevated temperature the reverse reaction of alkyl radical addition to molecular $\mathrm{O}_{2}$ (i.e the dissociation of $\mathrm{RO}_{2}$ into $\mathrm{R}$ and $\mathrm{O}_{2}$ ) is thermodynamically more favored. Consequently, the low temperature chemistry is hindered and no LTHR is seen at high intake temperatures.

The figures showing $600 \mathrm{rpm}, 149^{\circ} \mathrm{C}$ and $900 \mathrm{rpm}, 90^{\circ} \mathrm{C}$ conditions can be found in Appendix C. In addition, it was observed that at $900 \mathrm{rpm}$ and $90^{\circ} \mathrm{C}$ (Appendix C), the magnitude of LTHR was less when compared with the $600 \mathrm{rpm}, 92^{\circ} \mathrm{C}$ condition (Figure 7). This shows that with the increase in the speed, LTHR is reduced which is consistent with the experimental heat release analysis. This is also attributed to the alkyl radical addition to $\mathrm{O}_{2}$ pathway. It was found to be true for FACE A surrogate and PRF 84.

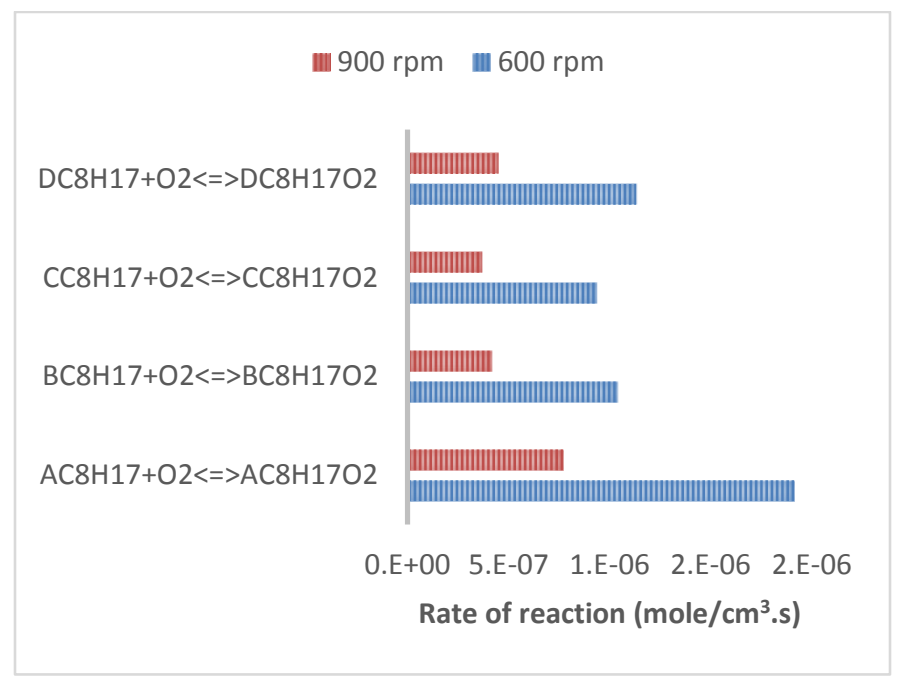

Figure 14: Rate of reactions at $600 \mathrm{rpm}\left(92^{\circ} \mathrm{C}\right)$ and $900 \mathrm{rpm}\left(90^{\circ} \mathrm{C}\right)$ for PRF 84

In order to investigate the effect of engine speed on LTHR, rate of reactions were studied at two different speeds for PRF 84. Figure 14 shows that at high speed condition, the rate of addition to $\mathrm{O}_{2}$ for the iso-octane radicals are higher. The high speed increases the in-cylinder temperature, which again decreases the rate of addition to molecular oxygen and hinders the low temperature auto-ignition chemistry.

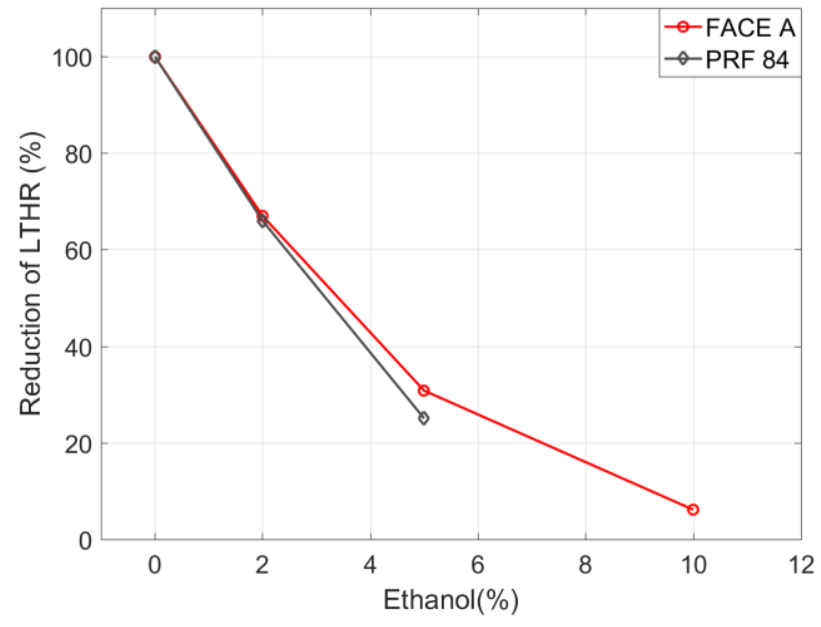

Figure 15: Simulated Percentage reduction of LTHR for $600 \mathrm{rpm}, 92^{\circ} \mathrm{C}$

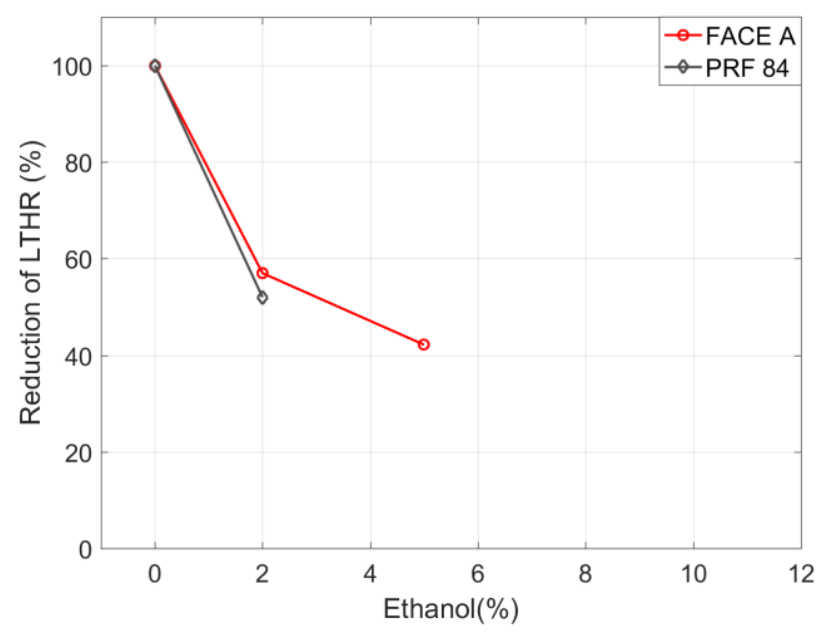

Figure 16: Simulated Percentage reduction of LTHR for $900 \mathrm{rpm}, 90^{\circ} \mathrm{C}$

Figure 15 and 16 shows the simulated percentage of reduction of LTHR with ethanol addition for both FACE A surrogate and PRF 84 at two engine speeds. The values are relative to E0 LTHR maximum. There are a few data points in the plots as it takes a small amount of ethanol to completely suppress LTHR in simulations, as seen before. It is observed that LTHR suppression is more effective for PRF84 in both cases. At $600 \mathrm{rpm}$ and, $92^{\circ} \mathrm{C}$, for $2 \%$ ethanol addition the rate of reduction for both base fuels is about the same. When increasing the ethanol percentage from $2 \%$ to $5 \%$, the rate of reduction for FACE A is faster compared to PRF 84. It can also be observed from Figure 7 (Simulated LTHR at $600 \mathrm{rpm}, 92^{\circ} \mathrm{C}$ ) that the base fuel matter the most at $5 \%$. At higher and lower concentrations, the base fuel matter less. At $900 \mathrm{rpm}$, for $2 \%$ ethanol addition, the LTHR decays faster for FACE A than PRF 84. Figure A4 (Simulated LTHR at 900 rpm, $90^{\circ} \mathrm{C}$ ) in Appendix $\mathrm{C}$ also shows the simulated difference due to base fuel. It is also observed that LTHR suppression tendency is dependent on the operating speed. At $900 \mathrm{rpm}$ it drops to less than $60 \%$ for both cases, while it's close to $65 \%$ for $600 \mathrm{rpm}$ case. Normalized value prevents the effect of the peak LTHR value on interpreting the results and focuses on the effectiveness of ethanol as a suppressant. Finally, it can be said that base fuel composition have a role to play

Page 7 of 16 
when it comes to blending octane tendency or the effectiveness of ethanol in suppressing LTHR.

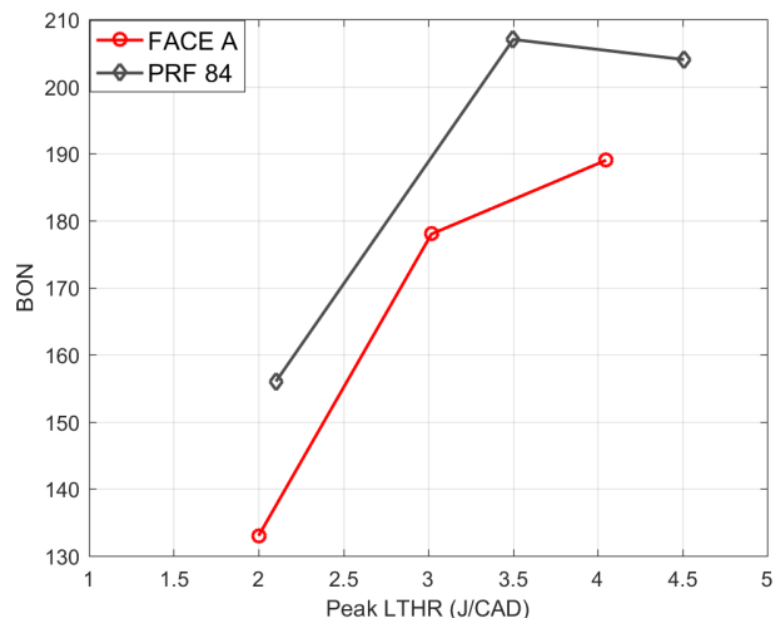

Figure 17: Experimental Blending Octane number variation vs Peak LTHR at $600 \mathrm{rpm}, 52^{\circ} \mathrm{C}$

In order to further justify that the base fuel composition had an important role in blending behavior of ethanol, Figure 17 shows the experimental blending octane number variation with peak LTHR for both FACE A and PRF 84. The peak LTHR values are obtained from Figure 3. For the non-linearity to exist, the blending octane number has to be higher than the research octane number of ethanol, which is 108 [3]. The blending octane number values are taken from the previous publication of the author [25]. Different slopes for PRF 84 and FACE A highlights that base fuel composition has a role in the blending behavior of ethanol with base fuels. It could also be seen that as the peak LTHR decreases, BON decreases and therefore it can be concluded that the non-linear behavior is a function of reduction of LTHR. It is expected that with decreasing LTHR or increasing ethanol concentration the BON will approach RON of the ethanol.

\section{Conclusions}

The non-linear blending behavior of ethanol with PRF 84 and FACE A surrogate was investigated using the chemical kinetic simulations. The radicals responsible for the low temperature chemistry reactions were studied with the addition of ethanol. Following are the conclusions:-

- Ethanol acts as radical scavenger leading to reduction of $\mathrm{OH}$ radical and hence LTHR is suppressed.

- With a small addition of ethanol, LTHR was suppressed drastically. This suggests that ethanol is an effective octane booster at small concentrations.

- The evolution of $\mathrm{OH} / \mathrm{HO}_{2}$ helped to explain the chemical reasons behind the reduction of LTHR with ethanol addition.

- The magnitude of LTHR depended on the engine operating conditions. At lower intake temperatures, LTHR was prominent but with the increase of temperature, no LTHR was detected. Speed effect on LTHR was secondary.

- The base fuel composition had an important role in the blending effect of ethanol. With ethanol addition to PRF 84 and FACE A, the simulated LTHR was found to be different. 


\section{References}

[1] Lee, S., Speight, J., and Loyalka, S., " Handbook of alternative fuel technologies, Second Edition," Ch: 1(16) and 12 (397), eBook ISBN : 978-1-4665-9457-9.

[2] Bhatia, S., "Advanced Renewable Energy Systems,(Part 1 and 2)," Ch: 16 (403), eBook ISBN: 978-1-78242-273-0.

[3] Foong, T., Morganti, K., Brear, M., Silva, G. et al., "The octane numbers of ethanol blended with gasoline and its surrogates," Fuel, 115: 727-739, 2014, doi:10.1016/j.fuel.2013.07.105.

[4] Yüksel, F., and Yüksel, B. et al, "The use of ethanolgasoline blend as a fuel in an SI engine," Renewable energy, 29 (7) : 1181-1191, 2004, doi.org/10.1016/j.renene.2003.11.012.

Chupka, G., Christensen, E., Fouts, L., Alleman, T. et al., "Heat of Vaporization Measurements for Ethanol Blends Up To 50 Volume Percent in Several Hydrocarbon Blendstocks and Implications for Knock in SI Engines," SAE Int. J. Fuels Lubr. 8(2):251-263, 2015 , doi:10.4271/2015-01-0763.

Rankovic, N., Bourhis, G., Loos, M., and Dauphin, R.,

"Understanding octane number evolution for enabling alternative low RON refinery streams and octane boosters as transportation fuels,"Fuel, 150: 41-47 , 2015, doi:10.1016/i.fuel.2015.02.005.

Ramadan, A., Sarathy, SM., Khurshid, M., and Badra, J., "A blending rule for octane numbers of PRFs and TPRFs with ethanol," Fuel, 180: 175-186, 2016, doi:10.1016/j.fuel.2016.04.032.

Anderson, J., Leone, T., Shelby, M., Wallington, T. et al., "Octane Numbers of Ethanol-Gasoline Blends: Measurements and Novel Estimation Method from Molar Composition," SAE Technical Paper 2012-01-1274, 2012, doi:10.4271/2012-01-1274.

Kalghatgi, G., "Fuel Anti-Knock Quality - Part I. Engine Studies," SAE Technical Paper 2001-01-3584, 2001, doi: $10.4271 / 2001-01-3584$.

Truedsson, I., Cannella, W., Johansson, B., and Tuner, M., "Development of New Test Method for Evaluating HCCI Fuel Performance," SAE Technical Paper 2014-01-2667, 2014, doi:10.4271/2014-01-2667. Atef, N., Kukkadapu, G., Mohamed, S., Rashidi, M. et al "A comprehensive iso-octane combustion model with improved thermochemistry and chemical kinetics", Combustion and Flame, 178: 111-134, 2017, doi.org/10.1016/j.combustflame.2016.12.029. Curran, H., Gaffuri, P., Pitz, W., and Westbrook, C., "A comprehensive modeling study of n-heptane oxidation," Combustion and Flame, 1998, 114(1-2), 149-177. doi:10.1016/S0010-2180(97)00282-4. Curran, H., Gaffuri, P., Pitz, W., and Westbrook, C., "A comprehensive modeling study of iso-octane oxidation," Combustion and Flame, 2002, 129 (3), 253-280, doi.org/10.1016/S0010-2180(01)00373-X.

Truedsson, I., Cannella, W., Johansson, B., and Tuner, M.,

"Engine Speed Effect on Auto-Ignition Temperature and

Low Temperature Reactions in HCCI Combustion for Primary Reference Fuels," SAE Technical Paper 2014-012666, 2014, doi:10.4271/2014-01-2666.

Truedsson, I., Tuner, M., Johansson, B., and Cannella, W.,

"Pressure Sensitivity of HCCI Auto-Ignition Temperature for Primary Reference Fuels," SAE Int. J. Engines 5(3):1089-1108, 2012, doi:10.4271/2012-01-1128.
[16] Andrae, J., and Head, RA., "HCCI experiments with gasoline surrogate fuels modeled by a semidetailed chemical kinetic model," Combustion and Flame, 2009, 156(4), 842-851, doi.org/10.1016/j.combustflame.2008.10.002. [17] Vuilleumier, D., Kozarac, D., and Mehl et al., "Intermediate temperature heat release in an HCCI engine fueled by ethanol/n-heptane mixtures: an experimental and modeling study," Combustion and Flame 161 (3) (2014) 680-695. doi:10.1016/j.combustflame.2013.10.008.

[18] Sarathy, SM., Oßwald, P., Hansen, N., and KohseHöinghaus, K.," Alcohol combustion chemistry," Progress in Energy and Combustion Science, 44:40-102, 2014, doi:10.1016/j.pecs.2014.04.003

[19] Truedsson I, Tuner M, Johansson B, and Cannella W., "Pressure Sensitivity of HCCI Auto-Ignition Temperature for Oxygenated Reference Fuels," ASME Journal of Engineering for Gas Turbines and Power, 2013;135(7):072801-072801-13. doi:10.1115/1.4023614.
[20] Kelly-Zion, P., and Dec, J., "A computational study of the effect of fuel type on ignition time in homogenous charge compression ignition engines," Proc. Combust. Inst, 28 (1): 1187-1194 , 2000, doi.org/10.1016/S0082-0784(00)80329-

[21] Kong, S., Marriott, C., Reitz, R., and Christensen, M. "Modeling and Experiments of HCCI Engine Combustion Using Detailed Chemical Kinetics with Multidimensional CFD," SAE Technical Paper 2001-01-1026, 2001, doi:10.4271/2001-01-1026.

[22] Reitz, RD., "Use of detailed chemical kinetics to study HCCI engine combustion with consideration of turbulent mixing effects ," J. Eng. Gas Turbines Power 124(3), 702707, 2002, doi:10.1115/1.1413766.

[23] Dec, J. and Sjöberg, M., "Isolating the Effects of Fuel Chemistry on Combustion Phasing in an HCCI Engine and the Potential of Fuel Stratification for Ignition Control," SAE Technical Paper 2004-01-0557, 2004, doi:10.4271/2004-01-0557.

[24] Frassoldati A., Cuoci A., Faravelli T., and Ranzi E., "Kinetic modeling of the oxidation of ethanol and gasoline surrogate mixtures", Combust. Sci. and Tech., 182: 653667, 2010. doi:10.1080/00102200903466368.

Waqas, M., Naser, N., Sarathy, SM., Morganti, K. et al., "Blending Octane Number of Ethanol in HCCI, SI and CI Combustion Modes," SAE Int. J. Fuels Lubr. 9(3):659-682, 2016, doi:10.4271/2016-01-2298

[26] Singh, E., Waqas, M., Johansson, B., and Sarathy, SM., "Simulating HCCI Blending Octane Number of Primary Reference Fuel with Ethanol," SAE Technical Paper 2017 01-0734, 2017, doi:10.4271/2017-01-0734.

[27] Zádor, J., Taatjes, C. A., and Fernandes, R. X., "Kinetics of elementary reactions in low-temperature autoignition chemistry," Progress in Energy and Combustion Science, 2011, 37(4), 371-421. doi: 10.1016/j.pecs.2010.06.006. Javed, T., Nasir, E., Es-sebbar, E., and Farooq, A., "A comparative study of the oxidation characteristics of two gasoline fuels and an n-heptane/iso-octane surrogate mixture," Fuel, 140: 201-208 , 2015, doi.org/10.1016/j.fuel.2014.09.095

[29] Chen, C., Wang, Z., Dagaut, P., and Sarathy, SM., "Jetstirred reactor oxidation of alkane-rich FACE gasoline fuels.," accepted to Proc. Combust. Inst., December, 2015. 
Selim, H., Mohamed, S., Dawood, A., and Sarathy, SM., "Understanding premixed flame chemistry of gasoline fuels by comparing quantities of interest .,"Proc. Combust. Inst., 36 (1) : 1203-1211, 2016, doi.org/10.1016/j.proci.2016.06.127.

Selim, H., Mohamed, S., Hansen, N., and Sarathy, SM., "Premixed flame chemistry of a gasoline primary reference fuel surrogate," Combustion and Flame, 2017, 179, 300311, doi.org/10.1016/i.combustflame.2017.02.008. .

Shankar, V., Al-Qurashi, K., Ahmed, A., Atef, N. et al., "Oxidation of Alkane Rich Gasoline Fuels and their Surrogates in a Motored Engine," Proc of the European Combustion Meeting, 2015.

[33] Ahmed, A., Goteng, G., Shankar, V., Al-Qurashi, K. et al,

"A computational methodology for formulating gasoline surrogate fuels with accurate physical and chemical kinetic properties," Fuel, 143: 290-300 , 2015, doi:10.1016/j.fuel.2014.11.022. for Predicting the Anti-Knock Behavior of Fuels and Engines," SAE Technical Paper 780080, 1978, doi: $10.4271 / 780080$.

[35] Kee, R., Rupley, F., and Miller, J., "Chemkin-II: A Fortran chemical kinetics package for the analysis of gas-phase chemical kinetics ," Technical Report, Sandia National Labs., Livermore, CA (USA), 1989.

Bugler, J., Marks, B., Mathieu, O., Archuleta, R. et al., "An ignition delay time and chemical kinetic modeling study of the pentane isomers ," Combustion and Flame 163 (2016)

138-156. doi.org/10.1016/j.combustflame.2015.09.014.

"Modeling ignition of a heptane isomer: improved thermodynamics, reaction pathways, kinetics, and rate rule optimizations for 2-methylhexane," J. Phys. Chem. A, 120(14): 2201-2217 , 2016, doi: 10.1021/acs.jpca.6b00907. Aronsson, U., Solaka, H., Lequien, G., Andersson, O. et al.,

"Analysis of Errors in Heat Release Calculations Due to Distortion of the In-Cylinder Volume Trace from Mechanical Deformation in Optical Diesel Engines," SAE Int. J. Engines 5(4):1561-1570, 2012, doi:10.4271/2012-01$\underline{1604}$.

Hwang, W., Dec, J., and Sjoberg, M., "Spectroscopic and Chemical-Kinetic Analysis of the Phases of HCCI
[34] Douaud, A. and Eyzat, P., "Four-Octane-Number Method

[37] Mohamed, S., Cai, L., Khaled, F., Banyon, C. et al.,

Autoignition and Combustion for Single- and Two-Stage Ignition Fuels," Combustion and Flame, 154(3): 387-409, 2008. doi:10.1016/j.combustflame.2008.03.019.

[40] Agudelo, J., Lapuerta, M., Moyer, O., and Boehman, A.," Autoignition of Alcohol/C7-Esters/n-Heptane Blends in a Motored Engine under HCCI Conditions ," Energy Fuels, 31(3): 2985-2995, 2017, doi: 10.1021/acs.energyfuels.7b00059.

[41] Haas, F., Chaos, M., and Dryer,F., "Low and intermediate temperature oxidation of ethanol and ethanol-PRF blends:

An experimental and modeling study," Combustion and Flame 156(12) (2009) 2346-2350. doi.org/10.1016/j.combustflame.2009.08.012.

[42] Dec, J., Yang, Y., Dernotte, J., and Ji, C., "Effects of

Gasoline Reactivity and Ethanol Content on Boosted, Premixed and Partially Stratified Low-Temperature Gasoline Combustion (LTGC)," SAE Int. J. Engines 8(3):935-955, 2015, doi:10.4271/2015-01-0813.

[43] Zhu, S., Wang, C., Qian, Y., Ou, L. et al."Numerical Simulation of the Effect of Ethanol on Diesel HCCI

Combustion using Multi-Zone Model," Applied Mechanics and Materials, Vols. 229-231, pp. 78-81, 2012. doi:10.4028/www.scientific.net/AMM.229-231.78.

\section{Contact}

Prof. Bengt Johansson

$\underline{\text { Bengt.Johansson@kaust.edu.sa }}$

\section{Acknowledgements}

The authors would like to thank Clean Combustion Research Lab for providing the engine experiment facilities. The published paper was supported by funding from King Abdullah University of Science and Technology (KAUST).

Page 10 of 16
Zhang, P., Ji, W., He, T, He, X. et al. "First-stage ignition delay in the negative temperature coefficient behavior: Experiment and simulation," Combustion and Flame, 2016, 1-10. doi.org/10.1016/j.combustflame.2016.03.002.

Gatowski, J., Balles, E., Chun, K., Nelson, F. et al., "Heat Release Analysis of Engine Pressure Data," SAE Technical Paper 841359, 1984, doi:10.4271/841359.

Hohenberg, G., "Advanced Approaches for Heat Transfer Calculations," SAE Technical Paper 790825, 1979, doi: $\underline{10.4271 / 790825}$

[47] Heywood, J., 1988, "Internal Combustion Engine Fundamentals", McGraw Hill, New York, 1989.

Woschni, G., "A Universally Applicable Equation for the Instantaneous Heat Transfer Coefficient in the Internal Combustion Engine," SAE Technical Paper 670931, 1967, doi: $\underline{10.4271 / 670931}$ 


\section{Definitions/Abbreviations}

\begin{tabular}{ll} 
aTDC & After Top Dead Center \\
CAD & Crank Angle Degree \\
CA50 & Crank Angle for 50\% heat release \\
CFR & Cooperative Fuel Research \\
CI & Compression Ignition \\
FACE & Fuels for Advanced Combustion Engines \\
HCCI & Homogeneous Charge Compression Ignition \\
HTHR & High Temperature heat release \\
IQT & Ignition Quality Tester \\
LTHR & Low Temperature heat release \\
PRFs & Primary Reference Fuels \\
RON & Research Octane Number \\
ST & Spark Timing \\
SI & Spark Ignition \\
TDC & Top Dead Center \\
\hline
\end{tabular}

Page 11 of 16 


\section{Appendix A:}

\section{Heat release analysis $[\underline{26,45-47]}$ :}

For each of the ethanol-base fuel blends, pressure data for 188 cycles were obtained from the pressure sensor mounted on the cylinder. The pressure data is obtained for both motoring and combustion cases. A pressure filtering process is applied to the data to make the traces smooth. Based on the engine geometry, a mathematical expression for the volume of cylinder expressed as a function of crank angle degree is obtained. Using the crank angle degree data of the engine obtained from the experiments, volume is calculated. The first law heat release analysis is used to derive the equation $A$ shown below: -

First law heat release can be given by:

$$
\frac{d Q}{d \theta}_{\text {Apparent }}=\frac{\gamma}{\gamma-1} \frac{P d V}{d \theta}+\frac{1}{\gamma-1} \frac{V d P}{d \theta}
$$

Equation A refers to the apparent heat release. A Matlab code is written which helps to calculate the rate of apparent heat release.

The ratio of specific heat $(\gamma)$ is estimated using a linear relation and is given by :-

$$
\gamma=\gamma_{o}-\frac{T_{c y l i n d e r}-300}{1000} . k \ldots \ldots \ldots \ldots(B)
$$

Following are the values used for both motored and combustion cases: -

\begin{tabular}{|c|c|c|}
\hline & $\gamma_{o}$ & $k$ \\
\hline Motored & 1.40 & 0.07 \\
\hline Combustion & 1.37 & 0.05 \\
\hline
\end{tabular}

The heat release was tuned for both motored and combustion pressure traces. For the motored trace, the tuning was performed to make sure that the heat release is close to zero as much as possible.

Heat transfer to the walls is based on the Woschini analysis [뇨]. It is given by:

$$
h=131 \times(\text { Bore })^{-0.2} \times \text { Incyliner Pressure } e^{0.8} \times \text { Incylinder Temperature }{ }^{-0.55} w^{0.8}
$$

Where

$$
w(\text { Charateristic gas velocity })=C_{1} \times 2.28 \times \text { Mean piston speed }+C_{2} \times 3.24 \times 10^{-3} \times \frac{V_{\text {displaced }}}{V_{I V C}} \times\left(\frac{P_{\text {fir }}-P_{\text {mot }}}{P_{I V C}}\right) \times T_{I V C}
$$

Where $C_{1}$ and $C_{2}$ were constants and tuned such that the heat release was close to zero for the motoring cases.

$V_{I V C}, P_{I V C}$ and $T_{I V C}=$ volume, pressure and temperature in the cylinder when the inlet valve closes. $T_{I V C}$ was assumed to be equal to inlet air temperature. $P_{I V C}$ was obtained from the experimental pressure data.

$P_{\text {fir }}$ and $P_{\text {mot }}=$ Burnt pressure and motored pressure trace

The heat release loss is given by:

$$
\frac{d Q}{d \theta}_{h t}=h \times \text { Area } \times\left(T_{\text {Incylinder }}-T_{\text {wall }}\right)
$$

The temperature of the walls was assumed to be equal to the coolant temperature and was assumed to be $370 \mathrm{~K}$. 


$$
T_{\text {Incylinder }}=\frac{\text { Pressure }_{\text {Incylinder }} x \text { Volume }_{\text {Incylinder }} x \text { Temperature }_{\text {IVC }}}{\text { Pressure }_{\text {IVC }} \times \text { Volume }_{I V C}}
$$

The net heat released in a cycle is the sum of the considered values:

$$
\frac{d Q}{d \theta}={\frac{d Q}{d \theta_{\text {Apparent }}}}_{\text {A }}+{\frac{d Q}{d \theta_{\text {heat loss }}}}
$$

The crevices and blow by losses were assumed to be negligible in this calculations.

\section{Appendix B}

\begin{tabular}{|l|r|r|r|r|}
\hline & \multicolumn{4}{|c|}{ Simulated Compression Ratios } \\
\hline Base fuel/ Ethanol & $600 \mathrm{rpm} / 92^{\circ} \mathrm{C}$ & $600 \mathrm{rpm} / 149^{\circ} \mathrm{C}$ & $900 \mathrm{rpm} / 90^{\circ} \mathrm{C}$ & $900 \mathrm{rpm} / 145^{\circ} \mathrm{C}$ \\
\hline FACE A surrogate / E0 & 12.62 & 11.50 & 14.10 & 12.80 \\
\hline FACE A surrogate / E2 & 13.00 & 11.63 & 14.58 & 12.92 \\
\hline FACE A surrogate / E5 & 13.60 & 11.73 & 15.35 & 12.98 \\
\hline FACE A surrogate / E10 & 14.90 & 11.83 & - & 13.00 \\
\hline PRF84/E0 & 12.65 & 11.56 & 14.30 & 12.80 \\
\hline PRF84/E2 & 13.15 & 11.68 & 15.00 & 12.90 \\
\hline PRF84/E5 & 14.20 & 11.75 & 16.00 & 12.92 \\
\hline PRF84/E10 & 15.40 & 11.84 & - & 12.95 \\
\hline
\end{tabular}

\begin{tabular}{|l|r|r|r|r|}
\hline & \multicolumn{4}{|c|}{ Experimental Compression Ratios } \\
\hline Base fuel/ Ethanol & $600 \mathrm{rpm} / 52^{\circ} \mathrm{C}$ & $600 \mathrm{rpm} / 149^{\circ} \mathrm{C}$ & $900 \mathrm{rpm} / 52^{\circ} \mathrm{C}$ & $900 \mathrm{rpm} / 149^{\circ} \mathrm{C}$ \\
\hline FACE A surrogate / E0 & 12.70 & 11.90 & 14.30 & 13.45 \\
\hline FACE A surrogate / E2 & 13.10 & 12.30 & 14.60 & 13.60 \\
\hline FACE A surrogate / E5 & 13.80 & 12.80 & 15.20 & 13.85 \\
\hline FACE A surrogate / E10 & 14.80 & 13.50 & - & 14.00 \\
\hline PRF84/E0 & 12.70 & 11.60 & 13.90 & 12.90 \\
\hline PRF84/E2 & 12.90 & 11.90 & 14.20 & 13.50 \\
\hline PRF84/E5 & 13.50 & 12.70 & 14.50 & 13.80 \\
\hline PRF84/E10 & 14.40 & 13.50 & - & 14.05 \\
\hline
\end{tabular}

Page 13 of 16 
Appendix C

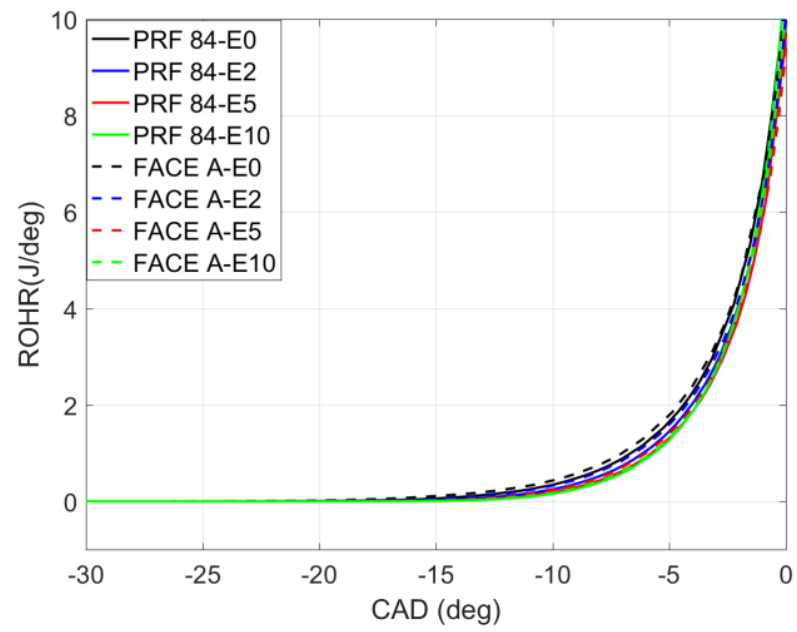

Figure A1: Simulated low temperature heat release for PRF 84 and FACE A, $600 \mathrm{rpm}, 149^{\circ} \mathrm{C}$

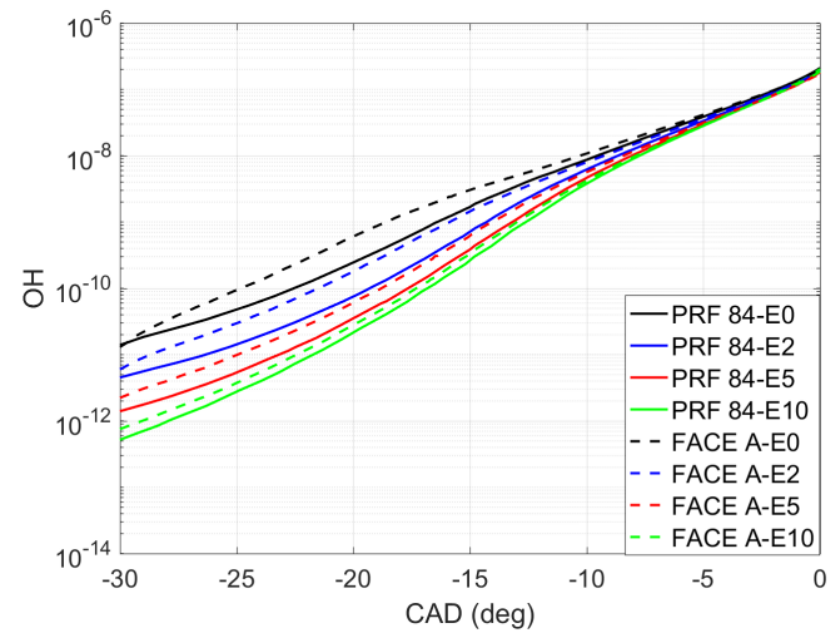

Figure A2: $\mathrm{OH}$ mole fraction for PRF 84 and FACE A, $600 \mathrm{rpm}, 149^{\circ} \mathrm{C}$ 


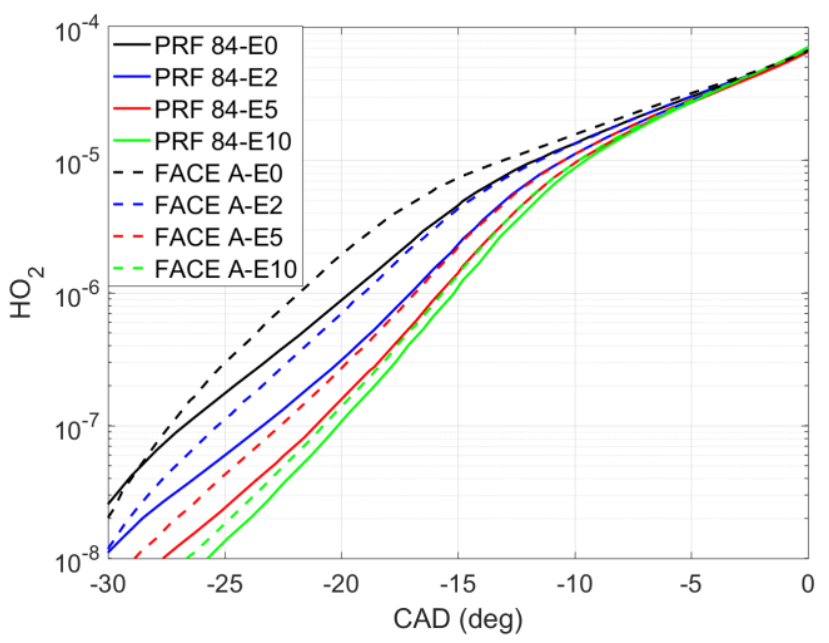

Figure A3: $\mathrm{HO}_{2}$ mole fraction for PRF 84 and FACE A, $600 \mathrm{rpm}, 149^{\circ} \mathrm{C}$

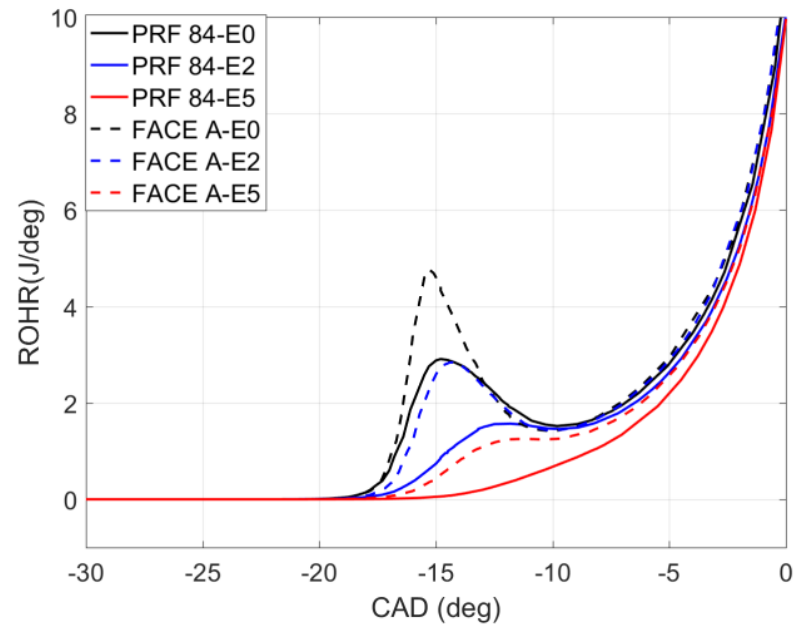

Figure A4: Simulated low temperature heat release (LTHR) for PRF 84 and FACE A, $900 \mathrm{rpm}, 90^{\circ} \mathrm{C}$

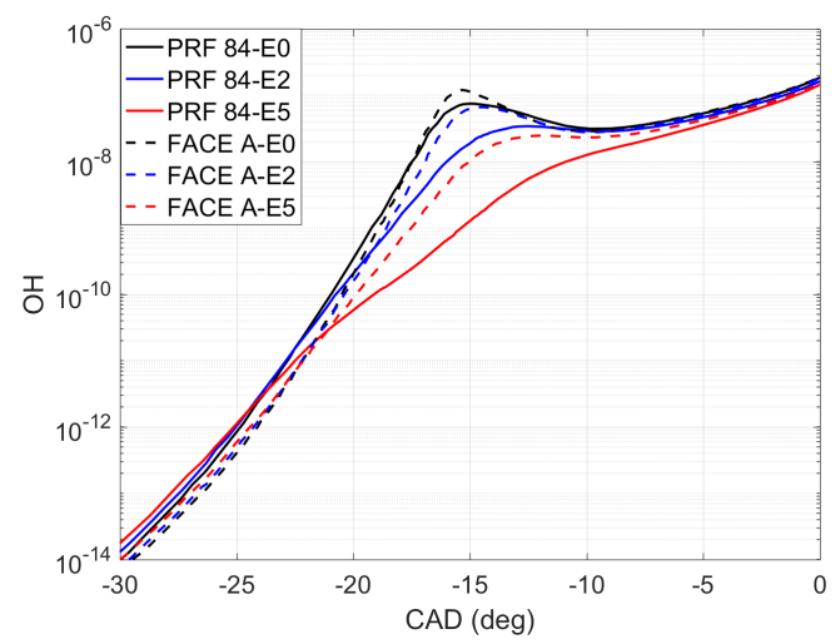

Figure A5: $\mathrm{OH}$ mole fraction for PRF 84 and FACE A, $900 \mathrm{rpm}, 90^{\circ} \mathrm{C}$

Page 15 of 16 


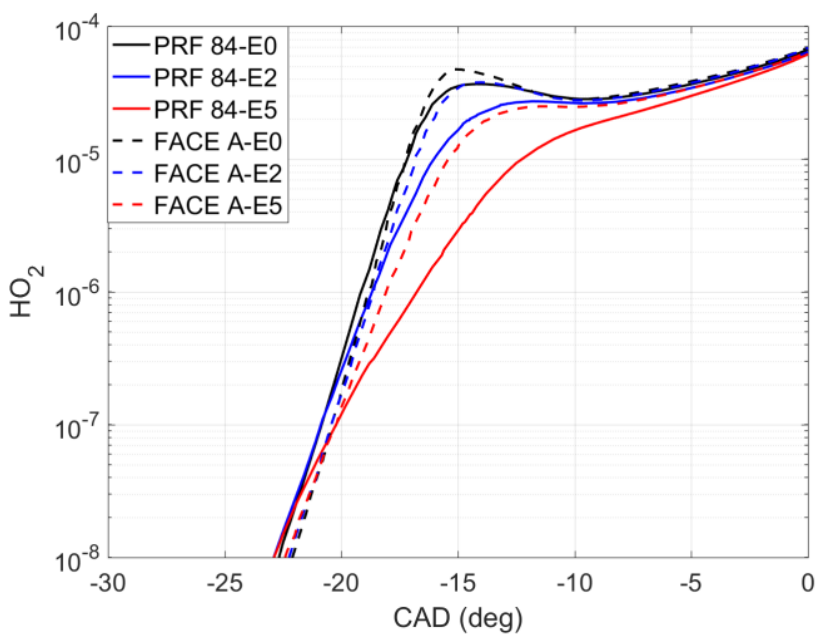

Figure A6: $\mathrm{HO}_{2}$ mole fraction for PRF 84 and FACE A surrogate, $900 \mathrm{rpm}, 90^{\circ} \mathrm{C}$

\section{Appendix D}

\begin{tabular}{|l|c|}
\hline Fuel Properties & FACE A \\
\hline RON & 83.9 \\
\hline MON & 83.5 \\
\hline Sensitivity & 0.4 \\
\hline Aromatic (\%) & 0.38 \\
\hline N-Paraffin's (\%) & 11.65 \\
\hline
\end{tabular}

Page 16 of 16 